\title{
Adaptive river network extraction method using local characteristics of water system?
}

\author{
Ying Zuo ${ }^{1}$, Fuzhou Duan ${ }^{1}$, and Hongliang Guan ${ }^{1}$ \\ ${ }^{1}$ Capital Normal University
}

May 27, 2020

\begin{abstract}
River network extraction is the basis of hydrological analysis and related issues. The accuracy of river extraction directly affects the accuracy of watershed related research. The key to extracting the river network by using hydrological analysis method is to determine the drainage area threshold. At present, there are existing methods for determining the drainage area threshold, which have problems such as inaccurate extraction with a single threshold and difficulty in obtaining data with multi-threshold. In view of this, based on DEM data of Jiuyuangou watershed in the Loess Plateau, combined hydrological analysis and digital terrain analysis methods, based on the principle of river network extraction from slope runoff, and taking into full consideration the hydrological characteristics of the terrain of the watershed, this paper proposes a threshold determination method based on multi-threshold constraints of local characteristics of the water system and compares the river network accuracy between the river network extracted by the threshold determined by this method and the single $\mathrm{t}$ value determination method and the river network extracted by the threshold determined by the river network density method. The results show that among the two river network quantitative indicators including average branch ratio and average length ratio, the corresponding values of the extracted river network by the threshold determined by the multi-threshold constraint method are 4.94 and 9.90 , which are the least different from the real river network (4.36 and 9.60), and the other two methods are quite different. The research results show that the river network extracted by the threshold determined by the multi-threshold constraint method can more realistically express the characteristics of the water system, and requires less data, which provides a new idea for determining the optimal the drainage area threshold for the DEM water system.
\end{abstract}

\section{Hosted file}

Adaptive water system extraction method using local characteristics of water system-Hydrological Proces available at https://authorea.com/users/326844/articles/454589-adaptive-river-networkextraction-method-using-local-characteristics-of-water-system 


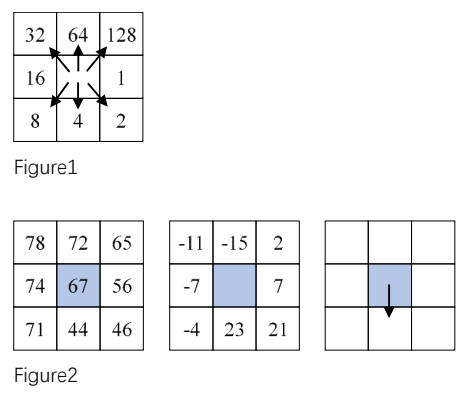

\begin{tabular}{|c|c|c|c|c|c|c|c|c|c|c|c|}
\hline 2 & 2 & 2 & 4 & 4 & 8 & 0 & 0 & 0 & 0 & 0 & 0 \\
\hline 2 & 2 & 2 & 4 & 4 & 8 & 0 & 1 & 1 & 2 & 2 & 0 \\
\hline 1 & 1 & 2 & 4 & 8 & 4 & 0 & 3 & 7 & 5 & 4 & 0 \\
\hline 128 & 128 & 1 & 2 & 4 & 8 & 0 & 0 & 0 & 20 & 0 & 1 \\
\hline 2 & 2 & 1 & 4 & 4 & 4 & 0 & 0 & 0 & 1 & 24 & 0 \\
\hline 1 & 1 & 1 & 1 & 4 & 16 & 0 & 2 & 4 & 7 & 35 & 2 \\
\hline
\end{tabular}

Figure3 


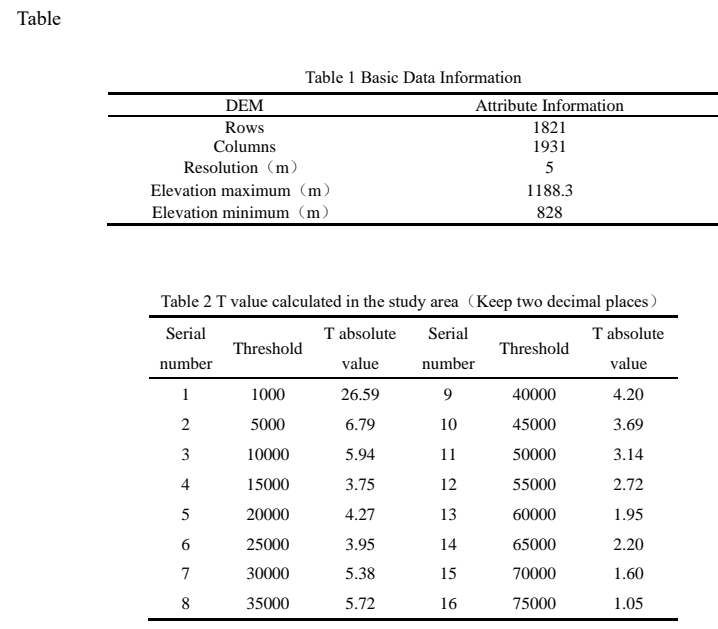

Table $3 \mathrm{~T}$ value calculated in sub-basin with code 1 (Keep two decimal places)

\begin{tabular}{ccccccccc}
\hline $\begin{array}{c}\text { Serial } \\
\text { number }\end{array}$ & $\begin{array}{c}\text { Thresho } \\
\text { ld }\end{array}$ & $\begin{array}{c}\text { T absolute } \\
\text { value }\end{array}$ & $\begin{array}{c}\text { Serial } \\
\text { number }\end{array}$ & $\begin{array}{c}\text { Thresh } \\
\text { old }\end{array}$ & $\begin{array}{c}\text { T absolute } \\
\text { value }\end{array}$ & $\begin{array}{c}\text { Serial } \\
\text { number }\end{array}$ & $\begin{array}{c}\text { Thresh } \\
\text { old }\end{array}$ & $\begin{array}{c}\text { T absolute } \\
\text { value }\end{array}$ \\
\hline 1 & 100 & 21.01 & 27 & 2700 & 4.99 & 53 & 5300 & 4.16 \\
2 & 200 & 17.12 & 28 & 2800 & 4.98 & 54 & 5400 & 3.89 \\
3 & 300 & 15.53 & 29 & 2900 & 5.00 & 55 & 5500 & 3.66 \\
4 & 400 & 14.96 & 30 & 3000 & 5.39 & 56 & 5600 & 4.17 \\
5 & 500 & 14.46 & 31 & 3100 & 5.02 & 57 & 5700 & 4.05 \\
6 & 600 & 14.05 & 32 & 3200 & 5.01 & 58 & 5800 & 3.98 \\
7 & 700 & 12.87 & 33 & 3300 & 5.76 & 59 & 5900 & 4.36 \\
8 & 800 & 11.11 & 34 & 3400 & 5.85 & 60 & 6000 & 4.28 \\
9 & 900 & 9.60 & 35 & 3500 & 5.71 & 61 & 6100 & 4.07 \\
10 & 1000 & 8.67 & 36 & 3600 & 5.39 & 62 & 6200 & 4.08 \\
11 & 1100 & 7.79 & 37 & 3700 & 5.32 & 63 & 6300 & 3.74 \\
12 & 1200 & 7.85 & 38 & 3800 & 5.20 & 64 & 6400 & 3.50 \\
13 & 1300 & 8.09 & 39 & 3900 & 4.97 & 65 & 6500 & 3.08 \\
14 & 1400 & 8.29 & 40 & 4000 & 4.97 & 66 & 6600 & 2.96 \\
15 & 1500 & 7.92 & 41 & 4100 & 4.67 & 67 & 6700 & 2.87 \\
16 & 1600 & 7.36 & 42 & 4200 & 4.56 & 68 & 6800 & 2.81 \\
17 & 1700 & 6.57 & 43 & 4300 & 4.50 & 69 & 6900 & 2.66 \\
18 & 1800 & 5.95 & 44 & 4400 & 4.33 & 70 & 7000 & 2.61
\end{tabular}

